\title{
Photo Displays and Intergenerational Relationships in the Family Home
}

\author{
Abigail Durrant ${ }^{1}$, Alex S. Taylor ${ }^{2}$, David Frohlich ${ }^{1}$, Abigail Sellen ${ }^{2}$, David Uzzell ${ }^{1}$ \\ University of Surrey ${ }^{1}$ \\ Guildford \\ Surrey GU2 7XH, UK \\ +44 1483300800 \\ Microsoft Research ${ }^{2}$ \\ Roger Needham Building, $7 \mathrm{JJ}$ Thomson Ave \\ Cambridge CB3 OFB, UK \\ +441223479700
}

\{A.Durrant; D.Frohlich; D.Uzzell\}@ surrey.ac.uk

\{Alex.Taylor; asellen\}@microsoft.com

\begin{abstract}
In this paper we describe a design-orientated field study in which we deploy a novel digital display device to explore the potential integration of teenage and family photo displays at home, as well as the value of situated photo display technologies for intergenerational expression. This exploration is deemed timely given the contemporary take-up of digital capture devices by teenagers and the unprecedented volume of photographic content that teens generate. Findings support integration and the display of photos on a standalone device, as well as demonstrating the interventional efficacy of the design as a resource for provoking reflection on the research subject. We also draw upon the theoretical concept of Dialogism to understand how our design mediates intergenerational relationships and interaction aesthetics relating to the notion of 'constructive conflict'.
\end{abstract}

\section{Categories and Subject Descriptors}

H5.m. Information interfaces and presentation (e.g., HCI): Miscellaneous.

\section{General Terms}

Design, Human Factors.

\section{Keywords}

Family photo displays, teen photography, situated displays, participatory design, interaction design, critical design, home life.

\section{INTRODUCTION}

Historically, the tools and practices of film photography have been more accessible to adults than juniors within the family home setting [21]. This is arguably due to the nature of the tools that comprise film photography, along with the cultural conventions and socio-economic factors surrounding their use [4].

In contemporary British society it appears that every member of the family home is doing photography. The advent of digital camera technology has coincided with the development of personal mobile devices, sparking the proliferation of photographic tools such as camera-phones and their availability

(c) The Author 2009.

Published by the British Computer Society to older teens (16-18) [12]. Processing costs and, in some cases, the cost of the camera itself are no longer a limiting factor. In light of this, many studies of contemporary family photography point to its 'apparent democratisation' [25, p.86]. Some claim that the role of photography in family representation is changing, along with the way photography mediates established domestic roles and practices [29]. Certainly, increased participation in photography has, together with its digitisation, led to novel uses and novel forms of representation [18]. Teens are seen to 'do' photography differently to their parents, or at least in ways that contrast with conventional practices such as family album-making [29]. For the purposes of this paper we highlight this distinction by adopting the term teen photography.

HCI researchers have made attempts to understand these two trends of democratisation and digitisation, and the associated changes to tools and practice, from different vantage points. For example, some studies have considered the take-up of novel capture tools such as camera-phones [12]; others have looked at the growing volume of collections and archiving strategies for their management [13]; others explore emerging cultures surrounding online display [18]. We consider these trends as they mediate the display of photos in the home. Digitisation has produced a new class of situated, dynamic and networkable display technologies that may be developed for home settings [20] and we deem it timely to explore how these technologies might support or transform domestic photo display mediated by new recruits and practices.

\subsection{Background \& Motivation}

In our ongoing research of family photo displays, we have observed the perpetuation of familial conventions surrounding film photography and its artifacts. In keeping with tradition, we see that the mother of the nuclear family continues to assume the roles of 'family photographer' and 'family chronicler' [21]. As we are focused on display, we've noted in addition how she coordinates the display of printed photos throughout the home environs on behalf of the household-at-large. We refer to this coordinating activity as home curation and see that it functions to unify a presentation of the family group, or household, throughout the home [28]. A feature of this role is that it affords a dominant voice to the mother for representing household members at home, especially juniors, and as such she is at liberty to impress a singular, maternal narrative upon home displays. According to our previous research [ibid.], home curation is intuitively tied to other roles that reproduce a domestic order, like parenting, housekeeping and interior decoration. These roles are all imbued with ethical sensibilities, power relations and moral obligations [27]. 
Given this relationship between photo display and the practical business of home, we wonder how digitisation and democratisation mediates intergenerational relationships and the representation of household members at home. Curation has been traditionally pursued through film-based practices such as framing prints and constructing photo albums [21]. Following digitisation, these practices can retain their character because digital photos can be printed [13]. However, as digital photography continues to pervade the home, the increasing volume and multiplicity of digital collections, their transmutability and the new technical competency required to handle them, all combine to increase the complexity of curatorial activity [ibid.]. In parallel, the increased participation of teens in photography presents potential competition to the curatorial voice [29]. Furthermore, teens are empowered by their technical competence with digital technology relative to mothers, with implications for household power dynamics [17].

This line of enquiry forms the basis of our research. The aim of our work and of this paper is threefold. Firstly, we aim to explore the politics of digital photo display in family homes and within the resident household group, specifically within the context of mother-teen relationships. Our second aim is to consider the ways in which these relationships might be supported or enriched by technologies that situate digital photos on a dedicated device beyond the desktop, with mind to informing a design space for domestic situated displays. In the discussion that follows, we describe an empirical field study engaging mothers and teenage daughters in family homes. In order to pursue our second aim we incorporate a practice-based design component to our study, which we describe. Our third aim is to assess the efficacy of this design component as part of our empirical work.

\subsection{Related work}

We will briefly contextualise our research aims within the literature. We establish family photography within the 'homemode of communication' in Anglo-American cultures that Chalfen has previously outlined [4]. Chalfen acknowledges the central role of film photography in family representation and draws attention to the ways in which familial and domestic conventions are reproduced through its tools and practices. Rose has picked up on this in relation to motherhood [21]. More recently, Drazin and Frohlich have considered how the specific presentational forms of traditional paper displays in the home are curated to communicate domestic roles, relationships and moral obligations, and can attribute salience to particular representations over others [5].

From the literature that follows photography's digitisation, it seems that the handling and presentation of photos is largely carried out in the digital realm and doesn't draw upon the ambient home environs in ways just described. Digital photos are largely managed and displayed temporarily on the desktop [13] or the TV [14], distributed for online display [18], and stored digitally [13]. They are often printed, but there is no reported use in the literature of commercial digital photo frames for curating home displays, nor have there been any empirical studies specifically investigating their use in family interaction. One exception is [19], in which the authors augment a digital photo frame to investigate distributed but not collocated family interaction. However this work is concerned with awareness rather than curation. Two recent studies present novel design concepts for displaying digital photos in the home based on observations of traditional displays and their handling [10, 26]. But these designs are presented in the context of ongoing ideation activities and not contextualised use. Therefore it is hard to ascertain how the practices that shape traditional home display might, in a real-world setting, translate to the adoption of a digital photo frame or similar class of dedicated photo display device. It is also hard to ascertain the potential value of such a device for family representation.

Though not related to photography per se, there is a growing number of studies on digital situated displays that inform our research [20]. For example, exploring person-to-place communication, the Homenote project [22] investigates the value of a specific site for displaying forms of digital messaging within a communal space of a family home. Findings reveal the significance of such a site for 'inscribing' personal identity at home, especially for juniors. It turns out that the ability to do this depends, not on the display technology made available in material terms, but on the domestic order established within the household. We are interested to explore how the findings from this study map to home curation. In particular, we wonder if teen photography and the content it generates provides juniors with an incentive to express identity in a similar way.

Finally, whilst there is a plethora of research on teen media practices and identity [e.g. 8], which can incorporate photography [e.g. 29], there are no studies to date that have explored how these practices might link to intergenerational relations and the curation of photo displays in family homes.

\section{APPROACH}

Our concern with photo displays and family representation has led us to adopt a phenomenological approach to empirical work that features people's relationships with each other and their photos. We employ two conceptual frameworks for this approach.

Firstly we find the work of Mikhail Bakhtin and, in particular, his concept of Dialogism [1] particularly useful for exploring the way in which people make sense of their personal photographic experiences relative to each other. Bakhtin has considered how interpersonal dialogue can enrich personal experience, including that which engages different and conflicting perspectives $[3,16]$. One of Bakhtin's main tenets is that dialogue with others is central to the formation, growth and expression of identity. In his conception of dialogue, one individual 'envelopes' another, 'enriching the other with an outside perspective' [16, p.112]. This process is positively transformative because dialogical activity has aesthetic and moral dimensions that are associated with meaning-making and democracy: it fosters mutual understanding (affinity); and selfworth. Dialogical relations extend to artifacts as well as people and have an intrapersonal dimension - an individual has multiple voices or self-narratives. McCarthy and Wright have effectively demonstrated the usefulness of Dialogism to HCI for understanding self-other relations in user experience [16]. We use the concept here to explore how intergenerational dialogue about home curation might signal the enrichment of intergenerational relations, based on the achievement of mutual understanding and self-worth.

We aim to shed light on the potential value of dedicated devices for digital photo display to teens and curators. To do this, we introduce a practice-based design component to our empirical work. In keeping with our dialogical framework, we adopt a critical approach to design that renders artifacts as a means to provoke reflection on the cultures of their users. This is described fully elsewhere [28]. Suffice to say here that it is closely aligned with the practice of Reflective Design set out by Sengers et al. [23] and includes some conceptual features of Critical Design [6]. We use design to establish a meaningful dialogue between ourselves, as designers and researchers, and our participating families, about our subject of enquiry. Beyond 
this, design is used to provide 'footholds for interpretation' that invite new ways of thinking about everyday experiences and relationships with people and display technologies [23]. This rationale is further explicated in $[2,24]$.

\subsection{Photoswitch}

We have designed a dedicated digital photo display device for use in our study. Photoswitch is not a prototype product but a thinking tool, or 'speculative resource' through which we provoke reflection and ideation around photo display at home. Its functionality is purposefully simple so as not be prescriptive in this regard. In many ways it is not unlike a Technology Probe [10]. The design was inspired during the analysis of our previous fieldwork for deployment in our ongoing field studies with families we have previously worked with [28]. We use it to continue a dialogue with them about teen photography and home curation and specifically to sensitise them to politics surrounding these phenomena and their integration. This underpins our rationale for deploying a novel device rather than an existing commercial one.
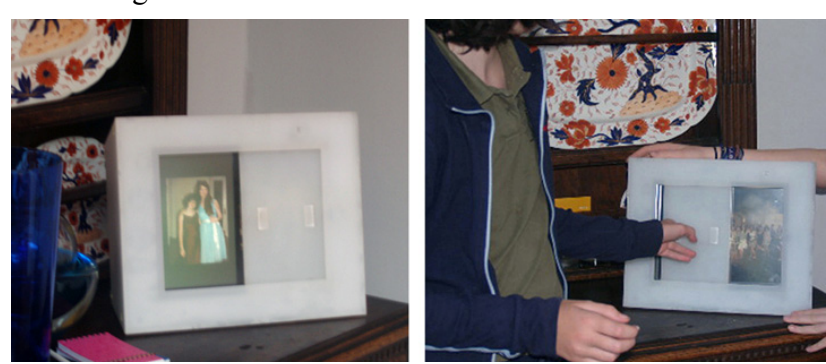

Figure 1: Photoswitch deployed in a family home.

Photoswitch comprises a standalone acrylic casement with two digital photo display regions and a spring-loaded, sliding door that constrains viewing to no more than one region at a time [Fig. 1]. Hence one region is displayed at the expense of the other. Two collections of digital photos are assigned to the display, one for each region. One region is to be allocated to a teenager and their collection, and the other to her mother and her collection. The sliding door presents a physical constraint that invites the teenager, her mother, and any other user, to enter negotiations for sharing a single photo display site. This constraint is devised specifically to provoke reflection on the process of negotiation involved in displaying two photo collections at home. Given this potential, Photoswitch is to be deployed in a communal space.

Addressing our interest in the novel affordances of digital display technology, we add a set of automatic behaviours to Photoswitch. A photo displayed on the region behind the door starts to fade to black over 15 minutes, at which point it is automatically replaced by another photo from the collection, by random selection. Sliding the door again before this point causes the faded photo to return to its original brightness but after this point reveals a new photo from the collection.

Let us explain the rationale behind this automation. We aim to provoke participants to consider (as a starting point at least), 'what does it mean to take one household member's photo off display and replace it with another's or even your own?'. To do this we create a particular set of conditions. Photoswitch enables limited manual control to change the photo on display: it cannot be used to select a particular photo for display; it only enables the removal of a particular photo from display. As we do not want people to use the sliding door as a manual switch to browse collections, we have found that the 15-minute 'effect' of the sliding door-as-switch is long enough to detract people from using it for this purpose. By presenting a particular context for interaction, Photoswitch serves to draw attention to the dynamic properties of digital photo displays whilst focusing on tensions surrounding their temporality for multiple users.

Photoswitch has additional features to those just described. It is equipped to capture and log sensor data including 'when' particular photos are displayed, enabling additional contextual information to be gathered from the deployment.

\section{Method \& Procedure}

Photoswitch was deployed in four nuclear family homes across the South of England. A mother and her teenage daughter (aged 17-18) from each household were recruited to participate directly in the deployment. All households comprise two or more daughters living at home with both parents. Households share socio-economic status (with a combined gross income of $£ 40-60 \mathrm{k}$ ). All have a shared computer with Internet access. All have their own digital camera and camera-phone. In Households Two and Four, teenage participants also have their own laptops and Internet access from their bedrooms. All participants took part in our previous research, represented in part elsewhere [28]. To support our sample selection: we previously found older teens to participate most actively in teen photography; we also found considerable gender differences; therefore for this current study we recruited only female participants and older teens, (although age, gender and crosscultural differences would be interesting to consider further in future work). Our analytic framework (to follow) determined our small sample size of four households and eight participants, for in-depth, longitudinal engagement.

In advance of the deployment, mothers and daughters were invited to each create a collection of 12 personal photos for display on Photoswitch in response to two tasks: select six photos that portray who you are; select six photos that portray your family. Each collection was loaded onto the device when deployed. Photoswitch was then deployed for approximately one month in each home, after which the researcher revisited and conducted a semi-structured interview with the dyads about their experience of the deployment. Towards the end of the interview the researcher invited participants to consider imaginary scenarios based on their experience: these are described as they feature in the results that follow.

We used Interpretative Phenomenological Analysis (IPA) to analyse the interview data, involving hermeneutical engagement with individual accounts of experience [15]. IPA was chosen because it recognises the dialogical positioning of our participants in relation to each other and also to us, the researchers, in making sense of the deployment. First we read the interview transcripts, eliciting key expressions made by participants as they made sense of the interview questions. Second, we made sense of the codes in the context of our research questions, in each household and then across the households. In keeping with IPA, generalisations across households were represented in the final themes, alongside idiosyncrasies peculiar to a given household. Note that Photoswitch's sensor data is not included in the analysis reported in this paper.

\section{FINDINGS \& DISCUSSION}

The experiences and insights that follow are triggered directly or indirectly from our participants' use of Photoswitch. In overview, we find that people bring expectations to the handling of digital photos on this novel device. Prior to using Photoswitch, all participants are familiar with the notion of photo display devices that cycle, randomly or sequentially, through a collection of digital photos, displaying one at a time. Accounts reveal that 'cycling' behaviours are now integrated into everyday home life and epitomised by the desktop 
computer screen-saver. Participants use the notion of 'cycling' to conceptualise the display of a photo collection at a site, made visible in the sections that follow.

All participants express their preference to display digital photos digitally rather than as prints, yet none have used a digital photo frame prior to the study. Digital photos have been viewed on cameras, desktop or mobile computers, or printed. Photoswitch is a novel intervention in this regard and is valued by all for enabling digital photos to be displayed on a dedicated device situated beyond the desktop. Three specific features of Photoswitch's design are found to be novel and instrumental in its use:

1. Two collections are on alternating display at one site;

2. Digital photos are displayed on a dedicated device;

3. Displays are changed manually and automatically.

As usage seems contingent on these features, we address them in turn and consider how they are made sense of by our participants for representational purposes.

\subsection{Two collections on alternate display}

Providing households with a single device to display two photo collections at one site reveals some interesting dynamics surrounding photo display and sharing in homes.

\subsubsection{Mutual interests and shared expressions}

We find Photoswitch provokes the mother (M) and daughter (D) dyads to express a mutual interest in each other's collections. Related to this, a shared significance is found in the different photo collections, particularly in how the family is seen to be represented. Indeed, this expression of family is often intended in the choice of photos for the collections. For example, the daughter of Household Two, D2, describes how the personal photos that she selected represent her 'closeness' to her household group, forged by their sharing of life experiences.

D2: Even when I had the choice of six photos of myself, like a lot of them are with my family because I guess we're quite close in that way. So it would be still on a personal level but it would have them in the memories.

Counter-intuitively perhaps, it is the switch mechanism and the need for turn-taking on Photoswitch that promotes this closeness between family members. For example, we find this creates the opportunity for D3 to share her personal photos with M3 and vice versa.

D3: It's quite nice to show photos that are my photos that Mum hasn't seen, that are now of my own and of my friends, which I haven't shown her yet. Or if I showed her she wouldn't normally look, [to M3] would you?

D3's words are echoed by all the teens: they all value the opportunity to show their mothers their photos on Photoswitch. The separate collections so appear, paradoxically, to bring the family together in some ways.

There is a subtlety to the expressions of family that is a consequence of Photoswitch's sequential display of different photos. Households exploit the changing or dynamic display by presenting multiple aspects of self and family. In the following excerpt from Household One, a junior (J), (aged 12 years and not part of the mother-teen dyad) joins the interview and offers her own perspective on her mother's and sister's Photoswitch collections.

J1:Well, it's quite nice to see the difference between other people's views. On one side there'll be a bridesmaid and, you think 'Oh family's all happy joyful occasions'; and on the other you see, sort-of, peaceful sides =

$\mathrm{M} 1:=\mathrm{D} 1$ 's rave party! =
D1:=Oh yeah, that was funny. $=$

$\mathrm{J} 1:=$ Lots of sort-of chaotic, happy occasions and there are two sides and there's always, like, a different view. So it's quite nice to see the different views.

M1:[To J1] Yes, and it goes public and personal.

Photoswitch offers alternative 'views' of this household's collective identity, which are 'nice' to see within the householdat-large.

Interestingly, effort is put into achieving some sort of balance in presenting the different sides of a family; Household Three even sets up rules to make sure each display region is alternated on a daily basis. In Household One, M1 takes this notion beyond Photoswitch's current functionality to advocate the design of a dedicated display region for each family member. Here we see an effort to cultivate the democratic representation of voices at home, through designated display 'channels' that have equal visibility.

\subsubsection{Tensions in self and family presentation}

Although the expression of alternative voices is valued, having separate collections also raises potential issues. Participants discuss the tensions concerning self-presentation within the household context. We can illustrate this by referring again to the excerpt from Household One, above, and the 'rave party photo'. As M1 observes, Photoswitch renders 'public and 'personal' dimensions visible. In the continuing discussion, M1 describes the photo as indicative of a 'side' of her daughter that the family doesn't ordinarily 'share' in - or 'connect' with. In turn, she questions its appropriateness for home display.

M1:[To D1] I was thinking your party one is a side of you that the family doesn't share in. So that's one of the ones, of course, that I don't like as much, cause I look at that and think 'Well, it's an okay one of D1, but I'd rather see one that connected in a different way.

D1: Yeah, there are loads of photos I didn't put on cause I didn't - it's completely separate from my home life.

D1 sympathises with M1's preferences, which confirm for her the 'separateness' of certain photos from her 'home life' and their necessary display beyond the household.

The deployment also lays bare the potential tensions that can arise when a daughter attempts to portray her mother.

M4: [To D4] you put one in of me where I was really sad!

D4: [To M4] That's the only photo I have of you.

M4: Ah [shudders] and I look so sad! I remember that day and I was sad. I didn't want to have my photograph taken. I think there's a bit of an exposing issue, definitely. I think 'Oh, you can't possibly show that! Why did you pick that?'. I felt like D4 might be trying to make a point.

D4: Yeah, I didn't pick it to be horrible, [to M4] it's just the only photo I have of you on your own.

M4: [To D4] Is it?

D4: [To M4] Yeah, I actually don't think we have any photos of you on your own.

M4: [To D4] That's sad, isn't it? We must remedy that.

Through their exchange, M4 and D4 proceed to make sense of the representational issues between them. As we shall see next, this leads them to re-consider how they might better coordinate the integration of their photos for home display.

\subsubsection{Curatorial control over teen}

Photoswitch's in-built mechanism of choosing between collections foregrounds how some of the tensions around selfpresentation are managed. In their use of Photoswitch, mothers 
and daughters both show willingness to select photos for home display that connect them appropriately to each other as family members. However, there remains a sense of who is the arbiter of family presentation.

D3: I would like to share some of my photos, but it's up to what Mum would really want. Graduation: now, see [to M3], that's an experience you could also be involved in, but a house party with my friends I don't think I really want to show Mum that, really! [To M3] Although they wouldn't be dodgy or anything! ... I'd show photos of me and my friends being sophisticated, or playing Pictionary! It's just other people coming round too.

Here, D3, the most tentative of the teenagers we interview, anticipates her mother's curatorial demands. At the same time, she seeks approval from parents and household visitors. Within the context of her household, she is compelled to present herself as a well-behaved daughter progressing towards adulthood: 'being sophisticated or playing Pictionary'. By doing so she projects a sense of accountability for maintaining good behaviour in peer activities. Her defensive talk about the 'house party' photos highlights her awareness of parental monitoring. It is in her interests to keep certain photos private whilst at the same time fostering intimacy with her mother.

Showing a similar sensitivity, mothers are seen to assert curatorial control whilst fostering intimacy with their daughters. The Photoswitch experience has led M4 to reflect on what it means for one member to represent another. She shows empathy within her curatorial role.

M4: I might get a folder together on the computer and ask [D4] you - you and J4 to come and look at it, and say 'Are you alright with this being on display downstairs?' because cause some things [on Photoswitch] didn't sit well with me I think I'd check out with you. Whilst I do - I take control, I think I might check out with you more now.

M4 expresses a new intention to liaise more closely with her juniors when curating displays. Curatorial control is still assumed, but it is now to be more informed by others. The degree to which mothers are prepared to collaborate during and following the deployment is seen to vary between the households. Whilst M2, M3 and M4's accounts resonate, M1 is less explicit about collaborating with others.

In sum, whilst distinguishing personal collections and potential conflicts of interest, there appears to be a moral endeavour by mother-daughter dyads to collaborate towards the integration of content in a way that meets with consensus. Photoswitch and its two-part collections operate within this system. However, as D4 points out, the contrived nature of the photo-selection task might have inhibited collaboration, if not deterred it. The 'sad photo' of M4, referred to by example, would've otherwise been filtered out.

D4: If we had sat down together and picked the photos I think we would've picked different things. [To M4] I wouldn't necessarily have put that picture in of you and stuff. Well, you wouldn't have let me anyway [laughs]. So it wouldn't end up on display.

In such instances, we also see how the dialogue about content is seen to promote, in an ambient and holistic sense, the aesthetic enrichment of photographic experiences in the communal space.

\subsection{Digital photos on a situated display device}

We have discussed some consequences of the integration of separate photo collections on Photoswitch. We now examine more closely the significance of place and the issues provoked by a display that allows two different collections to be combined.

\subsubsection{Order and arrangement}

The significance of place becomes apparent when, at interview, the researcher $(\mathrm{R})$ invites the dyads, as a thought experiment, to consider situating a number of digital photo display devices in alternative locations, based on their Photoswitch experience.

$\mathrm{R}$ : Where do you choose to put them?

D4: I think I would probably claim ownership over mine, and have it in my room.

M4: Yeah, that's how I would see it: you'd have one in your room, J1 would have one in her room, and =

D4: = And there'd be one downstairs somewhere. $=$

M4: = Yes I'd probably want a general one for in here that was a mixture of family things [to D4] because that's the way you use your Internet, isn't it? You've got your catalogue of photographs that are yours and they're not really ones that I look at.

Having to compose and choose between two personal collections on a single, situated device reveals an interconnection between ordering of domestic space and the ownership of digital content. A similar distribution and positioning of multiple devices is envisaged by all the participants: all envisage that teens - indeed, all juniors - would each have their 'own' devices for their 'own' photos whilst there would be a 'general' device in a communal space curated by the mother. This relates to the sense of ownership that participants feel over their Photoswitch display region at interview: all teens at some point distinguish ownership of their region; all mothers juxtapose this with an explicit interest in both regions.

\subsubsection{Mothers and communal spaces}

Communal areas of the home are places for displaying, in M4's words, 'general' photo collections and 'family things'. We therefore find that these places constitute and define the curatorial domain that mothers assume responsibility for. In addition, we find that curators are less compelled than their teens to territorialise a place to display personal photos that is independently owned. This is again reflected in their different preferences for situating Photoswitch.

\section{D3: I'd love one in my room - a digital photo display.}

M3: [To D3] Cause your room's quite personal to you, isn't it?

D3: Yeah, I would be more personal to me as well. I could choose more personal photos.

M3: I think still in [living room] here, for me because I quite like to share it, because even my room isn't just mine is it? I don't have a personal space any more, [to D3] do I?

In contrast to D3, M3 claims not to have a 'personal space' in the home, nor feels the need to claim one. She is happy to 'share' a general display device with the household. This is further expressed by the way in which D3 is 'territorial' over her Photoswitch display region whilst she is not: 'if it's changed I don't change it again cause I'm not that possessive'. M3's feelings are echoed by M2 and M4.

The territorialisation of display regions reflects intergenerational power dynamics. It seems that the mothers feel less of a desire to express territoriality in Photoswitch use because of their existing, implicit control of its positioning. For example, M2 refers to the kitchen of Household Two as 'my little kitchen'. This is where Photoswitch is deployed. 
M2: For me that was the best place (for Photoswitch) because I'm there so much of the day, maybe cleaning or putting the kettle on or cooking or whatever. [To D2] Maybe for you: I dunno.

D2: Yeah, well, I always come into the kitchen cause there's food here, so [laughs] so I get to see that.

In this case, the kitchen is presented as M2's domain that D2 comes into. In turn, there seems to be an implicit understanding of maternal ownership towards the device because the curatorial voice is salient in communal spaces.

D3: I guess we just took it in turns, but I think Mum's was on a lot longer than mine - I think it's because it's Mum's photos. I almost respect hers more than mine, maybe [laughs] cause it's her choice. $=$

M3: = I wouldn't mind if you showed your photo off.

D3: Yeah, but it's that kind-of parent-dominance thing. =

M3: = I think what happens is - because all my photographs weren't personal to me. It's more family [to D3] and yours were more yours, I think.

Despite her mother's democratic sentiments, D3 recognises the pervasivenness of conventions that determine 'parentdominance'. M3 accounts for this by asserting the familial as opposed to personal interests that her curatorship serves.

\subsubsection{Teens and personal space}

Given the salience of the curatorial voice, even with Photoswitch's twinned displays, it follows that teens invest more heavily in their personal spaces as sites for expression. Personal space is important to the teen for distinguishing her voice 'separately' from her household. For two of the four teens this is re-enforced through their ability to connect out of home from their bedroom using the Internet. Similarly, the ownership of personal photos and a place to display them are of great significance.

D4: Photos I've taken, or something, I feel quite protective over: 'That's for my display'; 'You can look at it if you want but it's not yours'.

M4: Yeah, I wouldn't expect to have anything to do with that at all.

Note the teen's sense of ownership and autonomy is mutually understood between mother and daughter.

However, the possibility of multiple display sites, distributed across the home, introduces a subtlety to the delineation of space and the potential networking of devices. Teens wish to be able to select photos for general display, but are not keen on the idea of receiving photos from others to their personal sites. All the mothers respond positively to this, agreeing that they wouldn't want to see their daughters' photos without permission and would rather be 'invited' to look. M3 discusses the possibility of distributed displays and considers how an interface at the general site might afford limited visibility to a collection of her daughter's photos.

M3: [to D3] It would be nice if it was like a folder that said 'Personal' and then you can share particular ones - you can just choose and change yours. We see: 'Okay, she's not sharing today'.

D3: [Laughs quietly.] Like: 'Blank'.

In these mother-daughter dialogues at interview, we see how the ordering of domestic space is negotiated. Accounts of use show that some displays and their content cement ideas of personal, private space where as others are treated as the province of the curator and the expressions of the wider family. Also demonstrated is the usefulness of Photoswitch as a thinking tool in dialogue. By necessitating the distribution and sharing of 'display space' on the device, its configuration sparks reflection about the distribution of space and - as the excerpt above shows, time - for displaying photos in the homeat-large. The temporal dimension of displays shall now be considered in more detail.

\subsection{Manual \& automatic change of displays}

Building on the above sections, we now turn attention to the control issues concerning the contextual handling of content on Photoswitch and how expressions of self and family are enriched or constrained by its material affordances.

\subsubsection{Local control of displays}

To recap, Photoswitch's automatic features are only triggered by manually sliding the acrylic door. The photo display doesn't change unless someone slides the door, a feature positively valued within all the households.

Participants also emphasise the significance of manually controlling what is displayed on Photoswitch when they are in its vicinity. With local control, they can directly manipulate displays for different audiences, including visitors, or for personal reflection. M1, for example, describes putting one of her photos on display for a visiting audience. This was kept on display until the visitors left. The person nearest to the device is thus sanctioned, so to speak, to engage with and control the content for the purposes at hand.

\subsubsection{Control as social mediation}

Participants also call upon Photoswitch to express themselves in the context of particular inter-personal exchanges, or moods. In the following excerpt, M2 uses the device to express feelings towards her daughter following an argument between them.

M2: If D2 had been a little bit down or had gone off whatever, I sort of wanted a reminder to remember her in a happy - a happier state. So I would put it across and I'd have her, sort-of, singing. I did that specifically one morning when [to D2] you were in a bit of a strop - downer and I thought I didn't want to have the day remembering her like that - I sort of wanted to have a happier D2 in my little kitchen. So I slid it across specifically and had her singing to me [laughs]. I found that quite significant. I actually really enjoyed that being able to do that. That was clear in my mind.

By 'specifically' selecting a photo on D2's display region, M2 is seen to use Photoswitch for two purposes: to express compassion towards her daughter; and to present a positive image of her daughter to herself as a means to transform the state of their relations in her own mind. M2's gesture is also seen to re-affirm domestic order in a space that she assumes relative dominance over - 'I wanted a happier D2 in my little kitchen'. M2's gesture adds to observations made in the previous section: mothers are 'not possessive' over their personal display region, finding their daughters' photos, at times, to be of equal significance to them. It seems that this behaviour is sometimes altruistic.

We see here how the sliding door feature - and the manual control it affords - is a resource for everyday expression and reflection, including intrapersonal dialogue, such as acts of remembering. Building on this, M2 greatly values the way that it makes multiple digital photos accessible to her in the course of her home life, something that she feels has only previously been afforded to her juniors.

M2: I loved it cause I'm in the kitchen a lot and - the girls have lots of reminders on their laptops - they've always got the screen-savers and they flick through all their photographs, but I'm not really technical in that way - so for me to come 
into the kitchen - and its so easy just to move the - and see a friendly face when I'm cooking.

M2 enjoys the ease with which she can access and 'flick through' digital photos in a place she spends time in.

The sliding door feature mediates everyday expression in other ways too. Notably, it invites playful engagement because it cultivates 'suspense' around what content might be revealed. This is seen to directly provoke dialogical exchange between mother and daughter. As M1 adds, the door can be a 'source of either conflict or family fun', highlighting some subtle aspects of etiquette associated with controlling and changing photo displays in a communal space. Some of these will be attended to next.

\subsubsection{Duration of displays \& shared significance}

Photoswitch presents a context for making preferences over photos and their display. This is partly because the door is used to display one photo collection over another. By making preferences, people make value judgments about photos. This sometimes creates conflict within the household, especially between teens and others.

D1: I get quite annoyed when people change the picture, sometimes. I want to take it back [grabbing gesture]! I like it when it's on my side!

In fact all participants said they had 'favourites' on Photoswitch. They make an effort to keep a photo on display that is preferable to an alternative in the other region, or until the photo of lesser value fades behind the door and is ready to be replaced.

D1:If it was one I really liked being replaced by one I didn't like I'd switch back to one that I liked and wait for the other one to fade. But I didn't mind if it was sort-of supplanted by another nice one.

M1: I'm going to change it so we can see! [Slides door.]

D1: Oh I like that one!

M1: See! [To D1] You love that one and I - we all - it stays on the bridesmaid one of you and my goddaughter a lot.

D1: Yeah! I haven't seen that one for ages!

M1: Oh, I don't know, it was there quite recently actually.

D1: Oh, I feel so cool that I went to this!

M1: So, we like that one.

We see here that the duration of display must be negotiated through photo-talk and turn-taking. This cultivates the mutual appreciation of photos - 'we like that one' - and self-worth - 'I feel so cool that I went to this'. When both in the vicinity, dyads establish a photo's shared significance by deciding together how long it should be displayed for. Here we see the dyads learning to work with the device's 'Veto' functionality: when a group is in the vicinity, a photo can be removed from display if any member wants it to be. Over a period of weeks this is seen to have an effect perceptible to the household-atlarge. In the excerpt above, the longevity of the 'bridesmaid' photo display is indicative of its relatively high significance to the household. This renders it salient within the household's curated displays.

It is apparent, then, that people continue to assign hierarchical value to photos at the site of display and in a social context. We see this as a form of in-display triaging, and a triaging that highlights the transformative processes of sense making between people and photos. Use of the sliding door somewhat embodies if not playfully catalyses this activity and its collaborative nature, as the above excerpt shows. We also find that in-display triaging familiarises the household with the content of collections and what it means to them as a group. This creates a sense of affinity between members. For example, we have numerous accounts of shared reminiscence around particular content that is positively valued for asserting family unity. We should note here that the process of employing IPA has enabled us to attend to how intergenerational affinity is forged between members at interview.

\subsubsection{Browsing and selecting content for display}

Leading from talk of triaging and 'favourites' is a discussion about what Photoswitch can't afford: the selection of a particular photo for display. This is deemed a negative and constraining feature of the experience.

M4: I quite enjoyed having it at first, I think, and I always flicked it when I went in the room - always flicked it. Yeah, and then I got disappointed if it wasn't the picture I wanted it to be at the other side [smiles].

During the deployment M4 wanted to browse and select her 'favourites' directly from the device at particular times and, because she couldn't, her appreciation of it deteriorated. Her disappointment provokes her to consider at interview what kinds of functionality she would ideally like from a display in the communal space.

M4: I quite like the idea of having a bigger one with more images on it, so that it's kinda like a collage of photographs. That would be quite nice to have that changing. There's a frustration thing of 'I wanna see another one'! =

D4: = Yeah, it doesn't change fast enough. $=$

M4: = We take so many pictures, [to D4] don't we? So just to have one and then two or three - it's just like 'Come on!' I'd just like to be able to flick around or pick a favourite.

Together with D4, M4 advocates a 'collage' view of a collection, in order to be able to browse or search for a favourite by 'flicking around' a relatively large number of photos quickly at the site of display. The other households advocate something similar, something to afford a 'bird's eye view'.

\subsubsection{Unexpected encounters with photos}

Whilst participants want to manually select photos on the device, they also appreciate its automatic features, in particular the way in which unexpected encounters with photos are generated. In addition to triggering suspense, play and frustration, such encounters can have an aesthetic quality that relates to being 'brought out of the moment' in the course of the mundane. This is a valued experience that often nurtures relationships with referents, as D2 describes.

D2: When I haven't like thought about my Nanna in like ages and it's just like 'Ah, Nan!', you know, and then it just makes you, like, have a little thought about her.

Alongside personal experiences, dyads also describe serendipitous instances of momentary shared reminiscence.

We note that these encounters take place partly because of the random behaviour but also because Photoswitch has multiple users acting on it manually. When asked, all dyads find it hard to ascertain whether or not the automated selection is random because, as they move in and out of its vicinity, they cannot know with certainty who might have changed the display and when. An over-arching feature of their experience is that they 'expect the display to change' and, more often than not, this has aesthetic value for them.

\section{DESIGN CONSIDERATIONS}

The deployment of Photoswitch has served to illuminate ways in which the integration of intergenerational photo displays mediates the social, moral ordering of home. We now consider 
how this integration might be supported by digital display technology situated beyond the PC's desktop. Photoswitch's efficacy as a tool for reflection on our subject of enquiry is also considered.

\subsection{Curation is enriched by teen narratives}

We have come to recognise the home's communal space as the curatorial domain. The introduction of a separate teen collection into this domain has provoked mothers and daughters to discuss the integration of personal collections and negotiate curatorial control. Using a dialogical lens $[1,3,16]$, we've seen how this has been an enriching experience for our dyads in terms of: understanding how both mother and daughter want to be represented as both part of the household and independent of it; creating a shared collection that is mutually appreciated as a representation of the household; and understanding the role of the mother-as-curator for family presentation. In the process, the curatorial domain is illuminated as a potentially significant site for teen photo displays in addition to other sites such as bedrooms, the web and personal devices.

The achievement of mother-daughter consensus is, perhaps, a surprising finding given the intergenerational conflict reported in previous studies of domestic technology use [e.g. 17]. In such studies, conflict is seen to largely stem from parents' lack of technical expertise with digital technology relative to their children. In this study, however, Photoswitch is introduced to homes as a novel device; photos are loaded onto the device by the researcher; and parents and teens are given equal opportunity to learn its functionality. Consequentially, such differences in technical expertise are not raised as an issue. As M2 points out above, curators' sense of efficacy using the mechanical switch to change photos is greatly appreciated.

Also, the finding concerning consensus contributes to a growing body of empirical work in the social sciences showing how mother-daughter dialogue that includes conflict can have positive and constructive features and outcomes [e.g. 9]. This is aligned with Bakhtin's theory that engagement with different and conflicting perspectives can enrich personal experiences. Indeed, this idea is promoted in contemporary psychological interventions for intergenerational conflict management: positive relations depend upon an interpretation of conflict as an opportunity for gaining new understandings rather than a threat to maternal authority; and interventions are made to promote epistemological 'growth' in mothers towards this end by fostering intrapersonal and interpersonal dialogue [ibid.]. Consequentially, such interventions are seen to foster self-worth in teens. Note that the achievement of maternal dialogical thinking around conflict is found to be more likely with the particular cultural background and socio-economic status that our participants have [ibid.].

Similar to such interventions, Photoswitch has enabled the achievement of dialogical understanding by offering a platform whereby the decision to display particular photos is opened up for discussion. Photoswitch's functional features are seen to structure the exchange that has ensued between mothers and daughters. In particular, whilst juxtaposing separate collections, the door (turn-taking) feature has also served as a positive constraint for coordinating and evaluating multiple perspectives of self and family at one site. This has encouraged curators to consider collaborating 'more' with their children and vice versa.

Reflecting upon opportunities for configuring situated display technologies at home [20,22], we suggest there is potential value in opening up multiple, dedicated photo display regions to the curatorial domain. These regions could 'channel' and juxtapose the dynamic display of individual members' personal photo collections. This idea signals a conceptual shift in thinking about tools for the photographic representation of family, away from affording a monological narrative via, for example, the family photo album, and towards a more dynamic and participatory family ritual. The negotiation of 'how', 'what' and 'when' content is to be displayed through these channels, and the relative salience of channels at any given time, is to be left in the hands of the family-at-large, at the site of display, if a design is to draw the interaction aesthetics of Photoswitch's interface that have been so positively valued during the deployment. As it remains necessary for the content displayed in the communal spaces to be curated to some degree, issues voiced by mother-curators' concerning their technical expertise and familiarity with digital display technology can be re-emphasised as a key consideration in the design of an interface for this kind of display device.

\subsection{Situating displays affords personal control}

The placement of Photoswitch in the curatorial domain has proven to influence its handling for coordinating the salience of family representations. This has provoked our dyads to discuss, in hypothetical terms, the kinds of additional, personal expression that could be afforded by situating photos in alternative places at home, communicating: the significance of personal space to teens and communal space to the curator; and, paradoxically, the significance of boundaries for intergenerational intimacy and affinity.

Particular configurations of photo ownership, distribution and arrangement have been established for rendering these significances, producing the notion of 'personal' versus 'general' devices for teen bedrooms and the curatorial domain respectively. Although the configurations are not necessarily generalisable, we see that each household draws upon place and its artifactual ecology to create its own system of displays, both in a real sense using Photoswitch and also in a hypothetical sense by creating imaginary scenarios of distributed, networked devices. A central feature of each system is the personal control that is afforded by place and its boundaries over who sees what where and when. Accounts have also revealed the subtle tensions that relate to the contextual meaning of photos and the sometimes contentious editing of personal collections. At times, these tensions render boundaries semi-permeable.

Display systems with networking potential could harness the dynamism inherent in digital imaging to afford contextual accessibility to photos at multiple sites, across physical and semantic boundaries. In design terms, this essentially means supporting an individual's creation and situated manipulation of multiple personal collections, which can be actively combined and recombined with other people's collections within and beyond the household. We have started to further explore this idea via design exercises that enable the networking of multiple collections across an ecology of display devices [e.g. 7].

\subsection{Dynamic presentations are valued}

The manual and automatic functionality for changing displays on Photoswitch has provoked discussion about the dynamic nature of personal and family presentations, not least because the control of displays is distributed between the household and the device itself. 'Addictive' and 'compelling', the door feature and photo-fading behaviour have invited change, conflict, play and negotiation, which have created attentiveness to collections. In sum, the limited control mechanisms for manually changing displays have produced: familiarisation with content of collections; a large number of significant family photos; personal favourite photos; contextual presentations of self and family; serendipitous encounters with photos; and expectations 
of change. Participants value these phenomena for supporting intergenerational expression and what might be referred to as 'constructive conflict' [9].

Indeed, we may use these phenomena to make sense of two notable requirements unfulfilled by Photoswitch: to browse multiple photos quickly at the display site; and to retrieve a 'favourite' photo at the display site. We take note of these requirements, along with the sense of ownership and place conveyed above, to consider the relevance of 'ownership' and 'audience' as classification labels to use in addition to other meta-data, for 'retrieving' digital photos at the display site.

Two implications follow from this. The first is that the ways in which criteria like 'ownership' and 'audience' are searched for on a standalone display device is heavily dependent on the nature of the device and where it is situated. As digital photos are made available beyond the desktop, display designs should be sensitive to how such criteria can be thought of differently by different users and in different places. Second, the search for photos using digital tags is not something to be simply automated. We find that, in Photoswitch use, the decisions and negotiations made on photo display are given high importance. New photo display devices may enable searches by drawing upon manual and automated tagging systems, but they should also leave room for joint decision-making about the meaning of content at hand and what we have referred to above as 'indisplay triaging'.

A further observation can be made here. In Photoswitch use, our participants wish to select 'favourites' from two pre-edited collections. Over the course of the deployment, participants have become familiar with the content of each other's Photoswitch collections, partly through via their ambient, automatic display, partly through others' manipulation of the displays, and partly through participants' own direct manipulation. This suggests that participants' memories for photos in the two collections are, to some extent, being continually rehearsed through their ambient engagement with the device. We consider this to be significant when comparing the search and retrieval requirements outlined here to those that may take place at the desktop. A recent study of desktop 'photowork' highlights the apparent lack of 'directed searches' for photos [13]. We speculate that the situatedness of Photoswitch produces ambient experiences with photos that have broader implications for search and retrieval requirements on dedicated, standalone display devices that are situated beyond the desktop. The potential difference between search and retrieval activities on the desktop versus beyond it would be worth exploring further in future studies. In particular, it would be interesting to explore these activities in terms of how they relate to a given display network and the community it engages, both within and beyond the family household.

\section{CONCLUSIONS}

When considering designs to support photo display in family homes, accounts from the study presented in this paper suggest that acts of display are as much directed by intergenerational relationships and domestic order as they are by the technologies that mediate them. The subtleties that we have observed in display practices may not have been articulated in the field using prototype products. As an alternative to deploying prototypes, Photoswitch has served as a 'speculative resource' for teasing out psychological tensions and opportunities surrounding teen photo display and home curation. Two specific design features of Photoswitch have proven useful towards this end: physical constraints for situating collections and structuring turn-taking; and limited control mechanisms for manually changing displays. Together, these features have afforded the representation of multiple voices in the field whilst fostering novel perspectives on intergenerational relationships between people and their photos. The design has prompted, if not catalysed, reflection on interaction aesthetics relating to interpersonal dialogue and the notion of 'constructive conflict' between mothers and their teenage daughters.

In turn, the findings are positioned to offer the HCI field a set of design considerations for photo display technology in the home. Insights from Photoswitch use inform a design space of situated and potentially networked displays, attending to the dynamism inherent in screen display, and the mediation of displays by family power relations and teen photography.

\section{ACKNOWLEDGEMENTS}

This work is supported by the Microsoft Research European PhD Scholarship Programme. Thanks extend to our research participants and to Michael Golembewski, Shema Tariq and Mark Champkins for their comments on early drafts.

\section{REFERENCES}

[1] Bakhtin, M. M., The Dialogic Imagination: Four Essays. In: Holquist, M. (Ed.), Emerson, C., Holquist, M. (Trans.), University of Texas Press (1981).

[2] Bell, G., Blythe, M. \& Sengers, P. Making by Making Strange: Defamiliarisation and the Design of Domestic Technologies. Trans. CHI, ACM Press (2005), 12, 2, 149173.

[3] Bell, M.M., \& Gardiner, M. (Eds.) Bakhtin and the Human Sciences: No Last Words, Sage Press (1998).

[4] Chalfen, R. Snapshot Versions of Life, Bowling Green State University Press (1987).

[5] Drazin, A. \& Frohlich, D. Good Intentions: Remembering through Framing Photographs in English Homes. Ethnos, Routledge 72, 1, (2004), 51-76.

[6] Dunne, A. Hertzian Tales: Electronic products, aesthetic experience and critical design. RCACRD Publications (1999).

[7] Durrant, A., Taylor, A.S., Taylor, S., Molloy, M., Sellen, A., Frohlich, D., Gosset, P., Swan, L. Speculative Devices for Photo Display. Proc. CHI' 08, ACM Press, New York, NY (2008), 2297-2302.

[8] Grinter, R.E., Palen, L. \& Eldridge, M. Chatting with Teenagers: Considering the Place of Chat Technologies in Teen Life. Trans. CHI, ACM Press, (2005) 13, 4, 423-447.

[9] Holmes, T., Bond, L. A., \& Byrne, C. Mothers' beliefs about knowledge and mother adolescent conflict. Journal of Social and Personal Relationships, Sage 25, 4, (2008), 561-586.

[10] Hutchinson, H., Mackay, W., Westerlund, B., Druin, A., Plaisant, C., Beaudouin-Lafon, M.,Conversy, S., Evans, H., Hansen, H., Roussel, N. \& Eiderback, B. Technology probes: inspiring design for and with families. Proc. CHI '03, ACM Press (2003), 17-24.

[11] Kim, J. \& Zimmerman, J. Cherish: smart digital photo frames for sharing social narratives at home. Ext. abs. CHI '06, ACM Press (2006), 953-958.

[12] Kindberg, T., Spasojevic, M., Fleck, R. \& Sellen, A. The ubiquitous camera: an in-depth study of camera phone use. Pervasive Computing, IEEE (2005), 4, 2, 42-50.

[13] Kirk, D., Sellen, A., Rother, C \& Wood, K. Understanding Photowork. Proc. CHI '06, ACM Press (2006), 761-770. 


\section{A. Durrant et al.}

[14] Lindley, S.E. \& Monk, A.F. Social enjoyment with electronic photo displays: Awareness and Control. In IJHCS (2008), 66, 8, 587-604.

[15] Lyons, E. \& Coyle, A. (Eds.) Analysing Qualitative Data in Psychology, Sage (2007).

[16] McCarthy, J. \& Wright, P. Technology as Experience. MIT Press (2004).

[17] Mesch, G.S. Family Characteristics and Intergenerational conflicts over the Internet. Information, Communication \& Society 9, 4, (2006), 473-495.

[18] Miller, A, D. \& Richards, W.K. Give and Take: A Study of Consumer Photo-Sharing Culture and Practice. Proc. CHI'07, ACM Press (2007), 347-356.

[19] Mynatt, E.D., Rowan, J., Jacobs, A. \& Craighill, S. Digital family portraits: supporting peace of mind for extended family members. Proc. CHI'01, ACM Press (2001), 333340.

[20] O’Hara, K., Perry, M., Churchill, E. \& Russell. D. (Eds.) Public and Situated Displays, Kluwer Press (2003).

[21] Rose, G. Family photographs and domestic spacings: a case study. Trans. Institute of British Geographers 28, (2003), 5-18.
[22] Sellen, A. Harper, R. Eardley, R., Izadi, S., Regan, T., Taylor A. S., \& Wood, K. R. Homenote: Supporting Situated Messaging in the Home. Proc. CSCW'06, ACM Press (2006), 383-392.

[23] Sengers, P., Boehner, K., David, S., Kaye, J., Reflective Design. Proc. CC'05, ACM Press, (2005), 49-58.

[24] Sengers, P. \& Gaver, W., Staying Open to Interpretation: Engaging Multiple Meanings in Design and Evaluation. Proc. DIS'06, ACM Press (2006), 99-108.

[25] Shove, E., Watson, M., Hand, M. \& Ingham, J. 2007. The Design of Everyday Life. Berg.

[26] Swan, L. \& Taylor, A.S. Photo Displays in the Home. Proc. DIS '08, ACM Press, New York, NY, 261-270.

[27] Taylor, A.S. \& Swan, L. Artful Systems in the Home. Proc. CHI'05, ACM Press (2005), 641-650.

[28] Taylor, A.S., Swan, L. \& Durrant, A. Designing Family Photo Displays. Proc. ECSCW '07, Springer (2007), 7998.

[29] Van Dijck, J. Digital photography: communication, identity, memory. Visual Communication, 7, 1. Sage (2008), 57-75. 